\title{
THE DIMENSIONS OF PSYCHOLOGICAL WELL-BEING OF CUSTOM EMPLOYEES DURING THE PANDEMIC
}

\author{
Vladislavs Sardiko \\ Daugavpils University, Latvia \\ Dzintra Iliško \\ Daugavpils University, Latvia \\ Jel̦ena Badjanova \\ Daugavpils University, Latvia \\ Svetlana Ignatjeva \\ Daugavpils University, Latvia \\ Valdis Jukšs \\ Daugavpils University, Latvia
}

\begin{abstract}
There has been a significant increase in interest about a psychological well-being among the researchers, politicians, media and general public. This study focuses on a measurement on a psychological well-being of the custom employees. For the purpose of measurement of a psychological well-being of custom employees, the authors have used Ruff's scale that includes such components as positive relationships with others, autonomy, competence, personal growth, a purpose in life, and self-acceptance. According to Ryff (2014), well-being has been investigated in relation to one's career pursuits. The purpose in life and personal growth were found to contribute to career commitments. In the case of the Latvian custom employees, among the essential elements of a psychological well-being are economic factors, favourable work environment and career opportunities in the organization. The study focuses in a psychological well-being of custom employees during the pandemic that leads to conclude that custom employees were in the forefront alongside with the doctors in stabilizing the situation in the county and have experienced a burn out, therefore they need a psychological support and a recognition of their efforts at work.
\end{abstract}

Keywords: custom employees, pandemic, psychological well-being, satisfaction with work.

\section{Introduction}

The COVID-19 pandemic presents a serious challenge for all people around the globe. In this unprecedent times, this is particularly important to pay attention to a well-being of those professionals who work in a forefront of pandemic. The focus of this study is a psychological well-being of the custom employees who 
Sardiko et al., 2021. The Dimensions of Psychological Well-Being of Custom Employees During the Pandemic

undergo anxiety and stress during their service. The authors have studied six aspects of a psychological well suggested by Carol Ryff (1995) among the custom employees.

The aim of the article is to carry out a subjective evaluation of a psychological well-being of custom employers by exploring how they maintain positive relations with others, how they exercise autonomy, competence, how pandemic influences their personal growth, the purposein life and a selfacceptance in relation to several factors, such as age, duration of service and education.

\section{Psychological Well-being Defined}

Despite of the increased focus on a well-being in the research, there is still no universal definition of a term. The concept of a well-being is related to the quality of human life. The term extends beyond simply feeling good and being satisfied. The term was related to one's happiness, the absence of negative feeling and the presence of positive feelings in one's life. Well-being is a multidimensional and ambiguous concept based on both hedonic (subjective wellbeing) and eudaimonic (psychological well-being) elements. The results gained from the eudaimonic scales of a well-being have been reflected in more than 150 scientific journals. Psychological well-being was at the centre of attention of researchers since the time of Aristotele (Seligman, 2011) but still remains unexplored due its overly broad definition and blurred nature. Aristotele introduced the notion of "eudaimonia" to reflect one's virtues and an ability to develop one's full potential. The notion of a wellbeing was reflected in Aristotele's "Nichomachean Ethics," and has impacted the understanding of wellbeing in psychology. Similar concepts were reflected in Maslow's selfactualization theory. Later Carol Ryff has actualized the term in a broader way. Eudaimonia most often is discussed as opposite to hedonic well-being, that involves affective and pleasure component. A large portion of research has been devoted to a meaning of life as a part of eudaimonic well-being that was is also included in Ryff's model of a psychological well-being. As Heintzelman (2018) argues, there is a strong evidence that eudaimonic and hedonic aspects of wellbeing are strongly related. Chen et al. (2012) utilized a bifactor model to study the connectedness between eudaimonic and hedonic well-being. The eudemonic perspective includes the notions of happiness as well relates to self-determination, meaning in life, and self-realization (Ryan \&Huta, 2009).

Dodge et al. (2012) provides an overview on research on a well-being from Aristotle until nowadays. They see the concept as multidimensional and extremely complex notion for measuring. Carol Ryff (1989) perceived psychological well-being from the eudaimonic perspective that includes personal 
development and commitment to existential challenges of life. Ryffs (1989) defined the major aspects of the concepts, such as autonomy, environmental mastery, positive relationships with others, purpose in life, realization of one's potential and self-acceptance. Thus, both objective and subjective elements are being measured so far. Psychological well-being is related to both demographic factors (Lee et al., 2016), certain personality qualities (Dangi \& Nagle, 2015), and socioeconomic conditions (Boyce et al., 2010). Wright \& Hobfoll (2004) explore how employers' psychological well-being influences their performance at work. This is particularly topical during the pandemic and in times of crises. In their study, the authors Wright \&Hobfoll (2004) established a bivariate relation among psychological well-being, organizational commitment, and job burnout. Some researchers choose to focus mainly on one aspect of a well-being, such as satisfaction with life, omitting other aspects of well-being. Shah and Marks (2004) chose to focus only on happiness by omitting other important aspect as well. Besides of hedonic and eudaimonic aspects of well-being, added resilience, one's ability to come with the situation, and adopting health problem solving strategies.

Carol Ryff's six categories of well-being included the following: selfacceptance as evaluated in high level means positive attitude towards oneself, personal growth as openness to new experiences, improvement of oneself over time, a purpose in life that signifies one's belief that life has a meaning, positive relationships with others, one's ability to build strong empathic ties with others, to build strong human relationships with others, mastery, one's ability to resist social pressures, and self-acceptance.

\section{Well-Being in Times of Pandemic}

In a number of national contexts wellbeing is considered as a significant aspect of individuals' life. Individuals with higher level of resilience can cope better with the anxiety and difficulties at work and stressful situation at work. COVID-19 has left immense psychological impact on the community at large. There are a great number of studies that have been carried out with the aim to explore the relations between a mental wellbeing and distress during the pandemic (e.g. Gray et al., 2020). Socioeconomic disparities increased health issues and anxiety among the population therefore the situation at the customs created stressful working conditions at the customs as well. Custom employees were among many frontline workers who had to work in the midst of uncertainty and upheaval. The anxiety of working in such an environment indirectly increased employees' anxiety and risks to be infected. Employees demonstrated their resiliency in the face of disease outbreaks. They carried out their duties at the customs at great personal risk conditions. Additional stressors for the employees were loss of the relatives and family members due to pandemic, economic anxiety 
Sardiko et al., 2021. The Dimensions of Psychological Well-Being of Custom Employees During the Pandemic

from losing one's job and financial instability - these constituted clear dangers for the employees. Among the feelings experienced during the pandemic were social isolation, financial insecurity, and uncertainty about the future that elevated depression and feeling of politeness. Therefore, employees should be trained to identify early signs of stress/burnout at work that need to be tackled accordingly. Other practical measures include easing tensions within the workplace. Regular testing for anxiety and health issues might be useful for custom workers (The World Health Organization, 2020).

\section{Measurements of a Psychological Well Being}

Nearly 25 years ago the model of psychological well-being that was designed by Carol Ryff addressed omissions in formulations of positive human functioning defined in the 1980s (Ryff, 2014). Ryff (2014) has examined how well being changes across adults' lifespan, how well-being is related to work and community activities, and how it influences one's health. She sees adults as proactive meaning makers how can face various challenge at their work environment in building a resilience in the face of adversity.

This methodology was repeatedly subjected to a validation process. The best-known and most common version contains eighty-four statements. The methodology was adapted by Shevelenkova and Fesenko in 2005, and even later in 2007 by Lepešinskis. According to Shevelenkova and Fesenko (2005), psychological well-being manifests itself as a subjective feeling of happiness, satisfaction with oneself and one's life, and experiences related to one's basic values and needs. Shevelenkova and Fesenko (2005) consider psychological wellbeing as a subjective phenomenon and experiences that are closely related to the internal evaluation system of these experiences. Psychological well-being is based on a subjective assessment of oneself and one's life, as well as on the aspects of the individual's positive well-being.

\section{Research Methodology}

The main methodology employed in this research was an adopted version of Ryff's questionnaire (Ryff\& Keyes, 1995) for the custom employees by Shevelenkova \& Fesenko (2005) with the aim to examine their psychological well-being (The Scale of Psychological Well-Being (SPWB)). Riff's six-factor model can be applied as a sound theoretical framework for investigating customs employee's psychological well-being. The questionnaire consists of a series of statements reflecting the six areas of psychological well-being: autonomy, environmental mastery, personal growth, positive relations with others, purpose in life, and self-acceptance. The main advantage of the questionnaire is that it 
allows to measure and evaluate the objective and subjective aspects of a psychological well-being. The experience is characterized by a comparison of certain experiences with a norm, standard, and the ideal (Shevelenkova \& Fesenko, 2005). Respondents were asked to rate statements on a scale of 1 to 6 , with 1 indicating strong disagreement and 6 indicating strong agreement with the suggested statement. To prove the reliability and coherence of the survey questions, the authors used the Cronbach's Alpha criterion or scale coherence factor. In this sample, the Cronbach's Alpha coefficient was $\alpha=0.645-0.788$ in 6 subscales, which indicates to a good internal coherence of a scale. The Cronbach's Alpha coefficient of the psychological well-being scale is $\alpha=0.909$. The data was processed by the SPSS statistical package. Among the limitations to be mentioned are the self-reported assessments of a psychological well-being. Since the employees may provide desirable answers as competed to actual reality, the data was gathered and interpreted by the researchers who work directly in this organization and are familiar with the work conditions in the organization.

\section{Research Finding}

In total 82 employees took part in this study on a voluntarily bases. The data includes information about the age and work experience of employees who work in the customs. The average age of employees who took part in this research was forty-six. The average experience of employees who work in Customs is fifteen years.

The authors have calculated Mean and SD of all six indicators of a wellbeing, such as positive relationships with others, autonomy, competence, personal growth, the purposeof life and self-acceptance. As this is reflected in Table 2, education influences several indicators of well-being. Employees with Master level has higher level of autonomy, competence, and self-acceptance and a personal growth as compared with those with the Bachelor degree. Education serves as a motivating factor for one's personal growth and professional development.

There are some differences among the employees in relation to gender criteria. Female participants see higher purpose in life even in the conditions of pandemic and are able to develops higher resilience. They pay more attention to personal growth in comparison with the male colleagues. Female participants see a potential in themselves for growth and they are more open to new experiences. They choose the strategy to growth in their personal and professional life over the time more as compared to their male colleagues. There are more and more females with each year who choose to work at the customs. 
Sardiko et al., 2021. The Dimensions of Psychological Well-Being of Custom Employees During the Pandemic

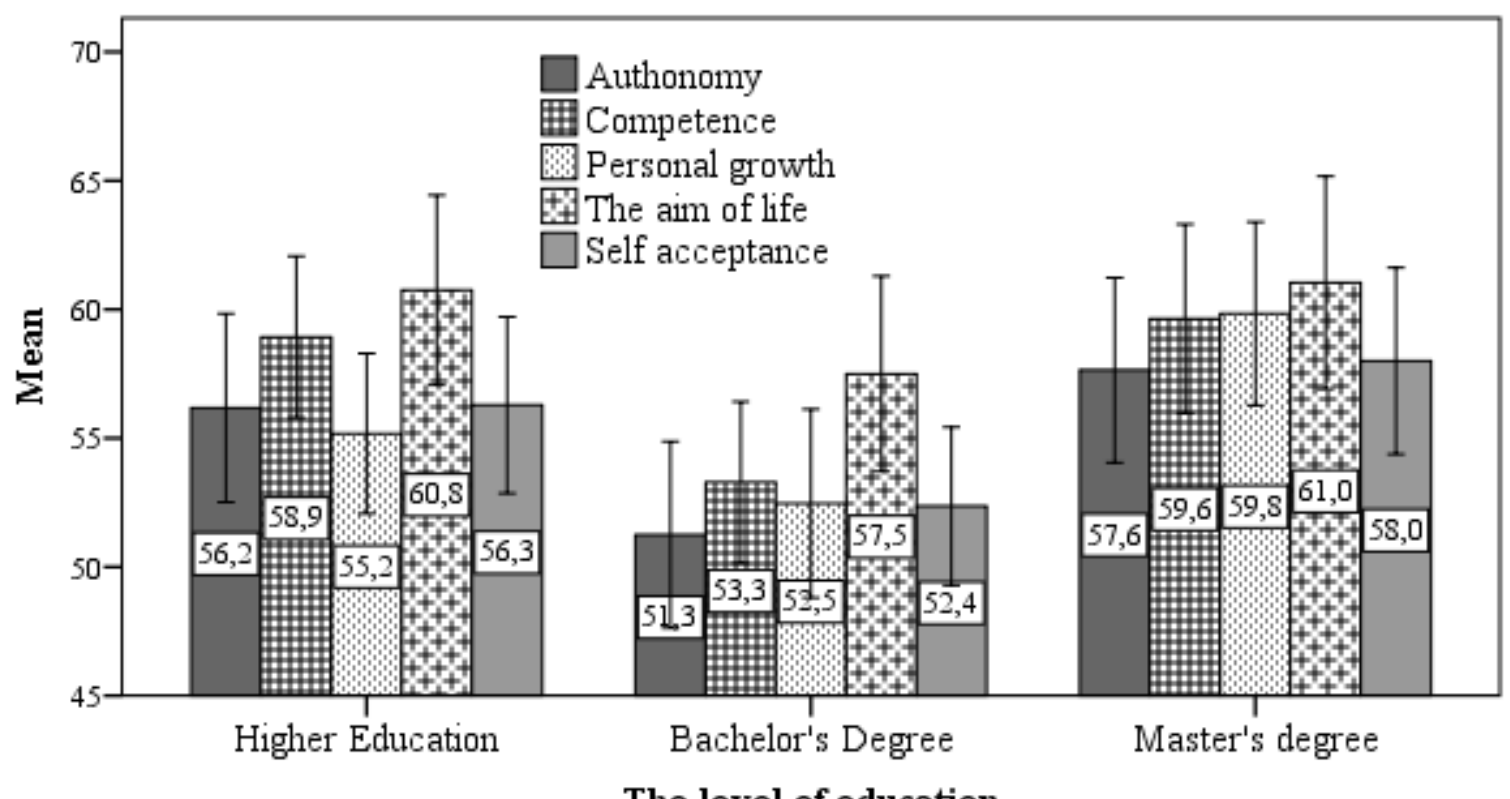

The level of education

Error bars: $95 \% \mathrm{CI}$

Figure 1 Indicators of Psychological Well-being and the Level of Education of Custom Employees

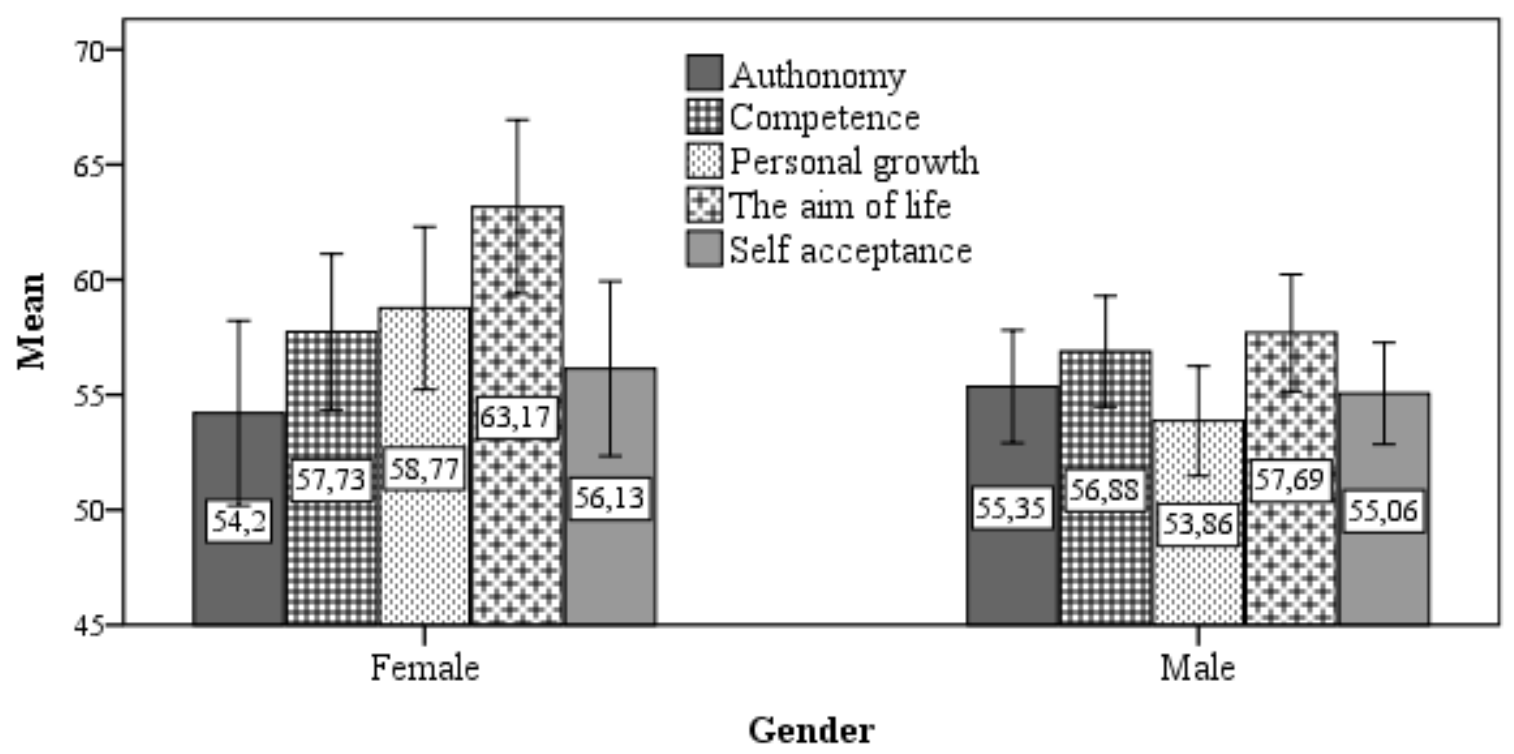

Figure 2 Indicators of Psychological Well-being and Gender of Custom Employees

The age and the duration of service in the customs of employee's was evaluated by the use of linear pair correlation coefficient or Pearson correlation coefficient. The correlation among the age and competence is significant, while in other cases correlation is not significant. Consequently, the age and the duration 
of service are not among the determining factors for a psychological well-being at the customs.

Table 1 Dimensions of psychological well-being of custom employees

\begin{tabular}{|l|c|c|}
\hline & F & Sig. \\
\hline Positive ralations with others & 1,310 & 0,276 \\
\hline Authonomy & 3,597 & 0,032 \\
\hline Competence & 4,761 & 0,011 \\
\hline Self acceptance & 4,794 & 0,011 \\
\hline The prpose in life & 1,111 & 0,335 \\
\hline Personal growth & 3,101 & 0,050 \\
\hline Psychological well-being & 4,606 & 0,013 \\
\hline
\end{tabular}

The results gained as a result of independent sample T- test, indicates the importance and significance of the purpose in one's life and a self-acceptance among the custom employees that is particularly significant during the pandemic in turbulent times.

Table 2 Psychological Well-being According to the Results of a T-test

\begin{tabular}{|l|c|c|c|}
\hline \multirow{2}{*}{} & \multicolumn{3}{|c|}{ t-test for Equality of Means } \\
\cline { 2 - 4 } & $\mathrm{t}$ & $\mathrm{df}$ & Sig. (2-tailed) \\
\hline Positive ralations with others &, 718 & 79 & 0,475 \\
\hline Authonomy &,- 526 & 79 & 0,600 \\
\hline Competence &, 422 & 79 & 0,674 \\
\hline Self acceptance & 2,404 & 79 & 0,019 \\
\hline The purposein one's life & 2,519 & 79 & 0,014 \\
\hline Personal growth &, 532 & 79 & 0,596 \\
\hline Psychological well-being & 1,310 & 79 & 0,194 \\
\hline
\end{tabular}

Self-acceptance that has gained the highest evaluation among the employees, includes positive attitude towards oneself and the acknowledgment of multiple aspects of oneself. Having a purpose in one's life, means sensing meaning in one's life by holding beliefs that life has a purpose and that this is worth living even during pandemic. 
Sardiko et al., 2021. The Dimensions of Psychological Well-Being of Custom Employees During the Pandemic

\section{Conclusions}

Psychological well-being is a complex construct and includes hedonic (pleasure, enjoyment), eudaimonic (meaning, fulfilment) and resilience (coping, healthy problem solving) dimensions. The absence of theoretically sound bases for explaining psychological well-being gave raise to overly broad definitions of the term and encourages researchers to define and measure well-being in various contexts. This study focuses on examination of well-being of custom employees. Psychological well-being is particularly important for the individuals in the situation of crises and pandemic.

For the purpose of this study, the authors chose a variation of Ryff's scale of psychological well-being methodology adapted by Shevelenkova and Fesenko in 2005 that focuses on eudaimonic dimensions of custom employee's psychological well-being. The sub-scale (authonomy) of a psychological well-being represents the lowest level among the other five sub-scales (autonomy, positive relationships with others, competence, existence of a purpose in life and self-acceptance). This might be explained by strictly normative nature of work at the customs. The average indicator of a psychological well-being was Mean $=341.94$

As it was discovered in this study, education is an important factor among the custom employees. Employees holding Master's degree have higher level of autonomy, competence, and self-acceptance and personal growth as compared with those with the Bachelor degree. Female participants see higher purpose in life even in the conditions of pandemic and are able to develop higher resilience. They pay more attention to a self-development as compared with the male colleagues.

Employees experienced the pandemic in their own unique way and a timeline. Some were dealing with illness or death in their immediate family, some have suffered from job insecurity and fear to get infected. Employees have to build resilience - the ability to handle situation, to maintain their energy in the face of changing demands, stressors and opportunities by being able to reflect, renew and realize their potential under pressure. Improvements in participants' ability to reduce their anxiety, depression and improve their sense of emotional control. This may be reached by regular testing of health issues and anxiety, by early identifying the signs of burnout at work and tackling them accordingly. Focusing on participant's sense of purpose, providing a support system, and building their resilience are among the tasks of the custom management. 


\section{References}

Boyce, C.J., Brown, G.D.A., \& Moore, S.C. (2010). Money and happiness: rank of income, not income, affects life satisfaction. Psychological Sciences, 21, 471-475.

Chen, F. F., Jing, Y., Hayes, A., \& Lee, J. M. (2013). Two concepts or two approaches? A bifactor analysis of psychological and subjective well-being. Journal of Happiness Studies, 14, 1033-1068.

Dangi, S., \& Nagle, Y. (2015). Personality factors as determinants of psychological wellbeing among adolescents. Indian Journal of Health and Wellbeing, 6(4), 369-73.

Diener, E. (1984). Subjective well-being. Psychological Bulletin, 95, 542-575.

Diener, E., Oishi, S., \& Tay, L. (2020). Psychological well-being, self-determination, and meaning in life. In E. Diener, S. Oishi, \& L. Tay (Eds.), Handbook of well-being. (pp. 1-14). Salt Lake City, UT: DEF Publishers.

Dodge, R., Daly, A., Huyton, J., \& Sanders, L. (2012). The challenge of defining well-being. International Journal of Wellbeing, 2(3), 222-235.

Dombrovskis, V., Guseva, S., \& Capulis, S. (2017).General and professional stress of mobile and operational staff of private security companies. 4th International Multidisciplinary Scientific Conference on Social Sciences and Arts SGEM 2017, 2 (17), 153-160.

Gray, N.S., O'Connor, C., Knowles, J., Pink, Simkiss, J. Williams, N., and Snowden, R.J. (2020). The Influence of the COVID-19 Pandemic on mental well-being and psychological distress: Impact upon a single country. Frontline Psychiatry, 11. doi:10.3389/fpsyt.2020.594115

Heintzelman, S. J. (2018). Eudaimonia in the contemporary science of subjective well-being.

Lee, B., Lamichhane, D.K., Jung, D.Y., Moon, S.H., Kim, S.J., \& Kim, H.C. (2016). Psychosocial factors and psychological well-being: a study from a nationally representative sample of Korean workers. Industrial health, 54(3), 237-245.

Ryan, R. M., \& Huta, V. (2009). Wellness as healthy functioning or wellness as happiness: The importance of eudaimonic thinking (response to the Kashdan et al. and Waterman discussion). The Journal of Positive Psychology, 4, 202-204.

Ryff, C., \& Keyes, C. (1995). The structure of psychological well-being revisited. Journal of Personality and Social Psychology, 69, 719-727.

Ryff, C. (2014). Psychological well-being revisited: Advances in the science and practice of eudaimonia. Psychother Psychosom, 83, 10-28, doi: 10.1159/000353263

Ryff, C. D. (1989). Happiness is everything, or is it? Explorations on the meaning of psychological well-being. Journal of Personality and Social Psychology, 57(6), 1069-1081.

Shevelenkova, T.D., \&Fesenko, P.P. (2005). Psyhologicheskoje blagopoluchije lichnosti. Psyhologicheskaya Diagnostika, 3, 95-129.

Shah, H., \& Marks, N. (2004). A well-being manifesto for a flourishing society. London: The New Economics Foundation.

Tang, Y-Y, Tang, R., \& Gross, J.J. (2019). Promoting psychological well-being through an evidence-based mindfulness training program. Frontiers in Human Neuroscience, 13, 237.

World Health Organization. (2020). Mental health and psychosocial considerations during the COVID-19 outbreak. Retrieved from https://www.who.int/publications-detail/mentalhealth-and-psychosocial-considerations-during-the-covid-19-outbreak 
Sardiko et al., 2021. The Dimensions of Psychological Well-Being of Custom Employees During the Pandemic

Wright, T. A., \& Hobfoll, S. E. (2004). Commitment, psychological well-being and job performance: An examination of conservation of resources (COR). Theory and Job Burnout. Journal of Business \& Management, 9 (4), 89-406. 